\title{
Evaluation of Insulation Systems for the Optimal Design of High Voltage Pulse Transformers
}

Sylvain Candolfi ${ }^{1}$, Sebastian Blume ${ }^{2}$, Davide Aguglia ${ }^{3}$, Philippe Viarouge ${ }^{1}$, Jürgen Biela ${ }^{2}$, Jérôme Cros $^{1}$

${ }^{1}$ LEEPCI Lab, Québec, Canada, ${ }^{2}$ ETH Zürich, Zurich, Switzerland, ${ }^{3}$ CERN, Geneva, Switzerland

Keywords: High voltage, insulation system, pulse transformer

\begin{abstract}
This paper presents a study for the design of the insulation systems of high voltage pulse transformer based on experimental tests and numerical simulations. Data of high voltage tests on solid and liquid insulation materials are presented and discussed. The understanding of each part of the insulation is supported by electrostatic fields simulations.
\end{abstract}

Presented at: IEEE IPMHVC, 1-5 June 2014, Santa Fe, US

Geneva, Switzerland

January,2015 


\title{
Evaluation of Insulation Systems for the Optimal Design of High Voltage Pulse Transformers
}

\author{
Sylvain Candolfi ${ }^{1}$, Sebastian Blume ${ }^{2}$, Davide Aguglia $^{3}$, Philippe Viarouge ${ }^{1}$, Jürgen Biela ${ }^{2}$, \\ Jérôme Cros 1 \\ ${ }^{1}$ LEEPCI Lab., Electrical and Computer Eng. Dept., Laval University, G1V 0A6 Quebec (QC), Canada \\ Emails: sylvain.candolfi.1@ulaval.ca, philippe.viarouge@gel.ulaval.ca,jerome.cros@gel.ulaval.ca \\ ${ }^{2}$ ETH Zürich, Laboratory for High Power Electronics (HPE), ETL F13 Physikstrasse 3, 8092 Zürich, Switzerland \\ Emails: blume@hpe.ee.ethz.ch, jbiela@ethz.ch \\ ${ }^{3}$ CERN - European Organization for Nuclear Research, Technology Dept., Electric Power Converter Group \\ CH-1211 Geneva 23, Switzerland Email: davide.aguglia@cern.ch
}

\begin{abstract}
This paper presents a study for the design of the insulation systems of high voltage pulse transformer based on experimental tests and numerical simulations. Data of high voltage tests on solid and liquid insulation materials are presented and discussed. The understanding of each part of the insulation is supported by electrostatic fields simulations.

Index Terms - High voltage, insulation system, pulse transformer
\end{abstract}

\section{INTRODUCTION}

At CERN high voltage (HV) pulse transformers for klystron modulators are currently under study for the Compact Linear Collired (CLIC).

The insulation distances and materials are key parameters that determine the dynamic performances. They must be as small as possible but ensure that no breakdown will occur during the lifespan of the transformer.

Design directions for the insulation systems are presented. The study consists in classical destructive HV tests [1] combined with in Finite-Element Analyses (FEA) for the identification of the weak insulation point. Safety factors on breakdown fields, for each insulation system, shall be considered to cope with ageing and imperfections in the insulation material. The impact on the performances of the pulse transformer versus the selected safety factor is presented considering a transformer which meets CLIC specifications.

\section{INSULATION STRUCTURE}

An oil-based insulation is selected for its ability to efficiently evacuate the transformer's heat-losses. Coils are fixed on solid supports (Error! Reference source not found.). The top secondary-winding's wire of the high voltage coil is located near the grounded magnetic core. In order to reduce the peak electric field (related to the Schweiger factor), a half-pipe shaped conductor is added on the top of the HV coil to increase the radius of curvature. The whole transformer is immersed in oil.

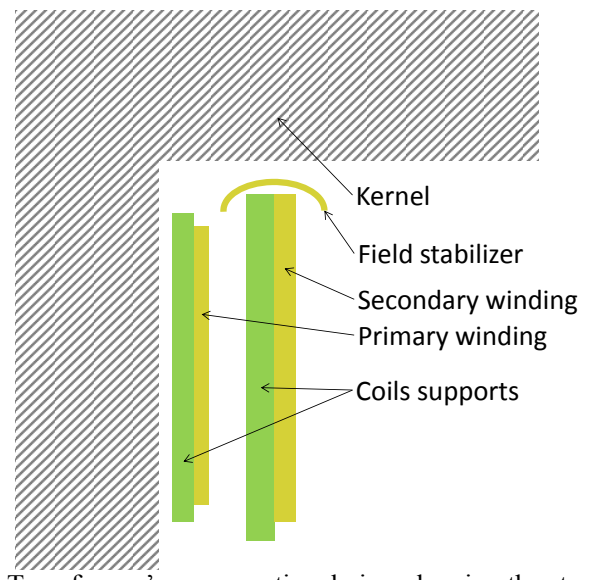

Figure 1. Transformer's cross-sectional view showing the structure of the insulation system.

\section{TESTS ON INDIVIDUAL INSULATION MATERIALS \\ 3.1 LIQUID MATERIAL}

Two types of synthetic insulating oils have been compared: MIDEL 7131 and RHODORSIL silicon oil. Used silicon oil has been tested and a comparison between used and new MIDEL oil has been carried out. The used oil was removed from transformers in operation at CERN. The different oils were characterized by their breakdown voltage and dispersion of the measurements. Rogowski electrodes with a gap of 1.8 $\mathrm{mm}$ or $3 \mathrm{~mm}$ have been used (Figure $2 \mathrm{a}$ ). A linearly increasing voltage of $500 \mathrm{~V} / \mathrm{s}$ is applied on the sample until breakdown. Results are presented in Table 1. Only a low decrease of the breakdown field between old and new MIDEL oil is observed but the standard deviation is larger because the impurities 
make the oil less homogeneous and trigger breakdown. We can deduce from those tests that the breakdown field in new MIDEL oil is about $20 \mathrm{kVmm}-1$ and decrease to $18 \mathrm{kVmm}-1$ with used oil. Used silicon and MIDEL oils cannot be fairly compared as they did not experience the same degradation conditions.

(a)

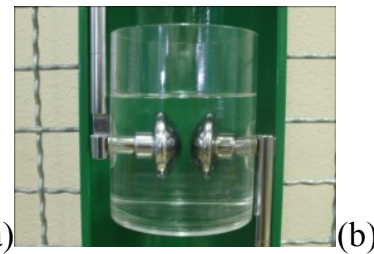

Figure 2. Rogowski electrodes for oil testing (a) and Setup for solid materials testing (b). Surface arcs around the PEEK plate are observed.

Table 1. Result of tests on oil. All averages are issued of 5 tests.

\begin{tabular}{|l|c|c|c|}
\hline \multicolumn{1}{|c|}{ Type of oil } & $\begin{array}{c}\text { Average } \\
\text { breakdown } \\
\text { voltage } \mathbf{V}_{\mathbf{b r}} \\
{[\mathbf{k V}]}\end{array}$ & $\begin{array}{c}\text { Standard } \\
\text { deviation }\end{array}$ & $\begin{array}{c}\text { Average } \\
\text { breakdown } \\
\text { field } \\
{[\mathbf{k V / m m}]}\end{array}$ \\
\hline Used RHODORSIL (gap 3 mm) & 39.0 & 8.9 & 13.0 \\
\hline Used MIDEL (gap 1.8 mm) & 34.3 & 13.6 & 19.1 \\
\hline Used MIDEL (gap 3 mm) & 54.4 & 7.2 & 18.1 \\
\hline New MIDEL (gap 1.8 mm) & 36.3 & 6.3 & 20.17 \\
\hline New MIDEL (gap 3 mm) & 61.1 & 5.0 & 20.7 \\
\hline
\end{tabular}

\subsection{SOLID INSULATION MATERIALS}

A plate of PolyEther Ether Ketone (PEEK) of $20 \mathrm{~cm}$ by 20 $\mathrm{cm}$ and $1 \mathrm{~mm}$ thickness has been tested between two $50 \mathrm{~mm}$ diameter electrodes (Figure 2b) applying a linearly increasing voltage. The breakdown voltage could not be determined because electric arcs at the surface occurred before breakdown through the plate. Breakdown occurred with an electrical field (inside the PEEK) of $80 \mathrm{kVmm}-1$. Therefore the PEEK breakdown field is greater than this value.

\subsection{WIRES}

Wires have their own layer of insulation. Enamelled wire and enamelled wire covered with one and two layers of mica strips have been tested in a copper braid connected to the ground (Figure 3). All the system is immersed in oil to avoid arcs between connectors, wire and grounded parts outside the copper braid.

The mica insulation enhance the breakdown voltage by more than a factor 10 (Table 2) but it does not depend on the number of layers of mica. The first layer of mica sheet is the most important as the electric field is larger near the wire where the curvature radius is the smallest. Furthermore interlayers air bubbles could have been trapped (no vacuum filling process) increasing partial discharges and consequent arc discharges.

Table 2. Breakdown voltage for different types of wires.

\begin{tabular}{|l|c|}
\hline \multicolumn{1}{|c|}{ Type of wire } & Breakdown voltage [kV] \\
\hline Enamelled wire & 3.4 \\
\hline Mica, one layer & 42 \\
\hline Mica, two layers & 35 \\
\hline
\end{tabular}

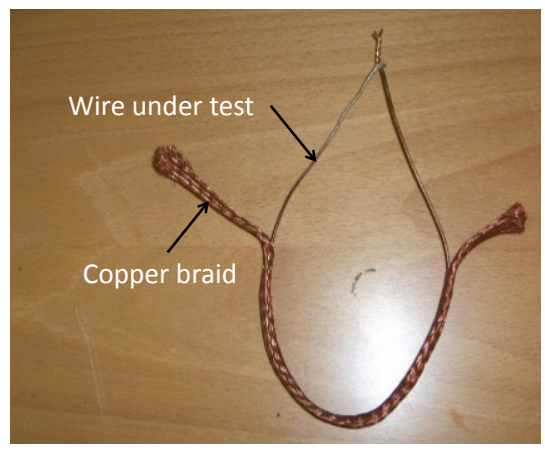

Figure 3. Setup for the tests of wires.

\section{TEST OF THE FIELD STABILIZER}

In high voltage pulse transformers field stabilizers are used to reduce the electrical peak field occurring at the secondary turn with the highest potential. The transformer geometry investigated here considers the secondary turn with the highest potential directly as field stabilizer by increasing its radius (Figure 4a) [4].

\subsection{INVESTIGATED SETUP}

To develop a better understanding of the electrical field distribution at the field stabilizer surface, the geometry was investigated in a simplified setup, as shown in Figure $4 b$, where the high voltage is applied to two tubes with a fixed distance with respect to a grounded plate, representing the distance of the two field stabilizers to the top of core window. A DC ramp $(1000 \mathrm{~V} / \mathrm{s})$ is used to obtain the average breakdown voltages with the two mentioned new transformer oils for various distances, each with at least 6 samples. The geometric setup was then simulated in 2D-FEM to determine the electrical peak field (Table 3) for each distance at the respective breakdown voltage. Additionally, the field path with the most critical electrical field was identified, which is displayed in Figure 5a for RHODORSIL and 5b for MIDEL.

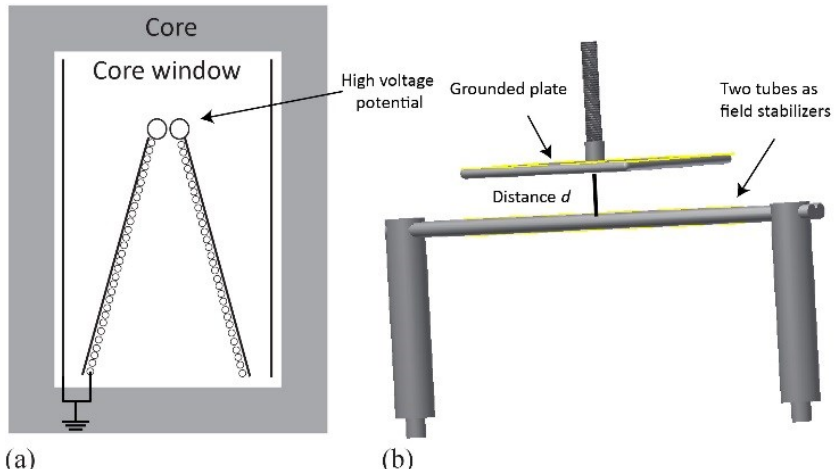

Figure 4. a) Transformer geometry with turn at the highest potential designed as field stabilizer. b) Simplified geometry representing the distance between the two field shape rings to the top of the core window. 


\subsection{RESULTS ANALYSIS}

The results, displayed in Table 3 verify the higher performance of MIDEL in comparison to RHODORSIL previously shown in Table 1 . They also show that the peak field is a key factor both in relatively homogeneous as well as in inhomogeneous electrical fields. The peak electrical field decreases from around $20.1 \mathrm{kV} / \mathrm{mm}$ to $15.5 \mathrm{kV} / \mathrm{mm}$ for RHODORSIL and from $26.8 \mathrm{kV} / \mathrm{mm}$ to $19.7 \mathrm{kV} / \mathrm{mm}$ for MIDEL with increasing distance. The decrease in electrical peak field is significantly smaller than for an assumed average electrical field $\left(E_{a v}=\frac{V_{b r}}{d}\right)$ (Table 1). Therefore it is crucial to consider in the design process the maximal electrical peak field rather than referring to an average electrical field for larger distances, which occur in a high voltage transformer.
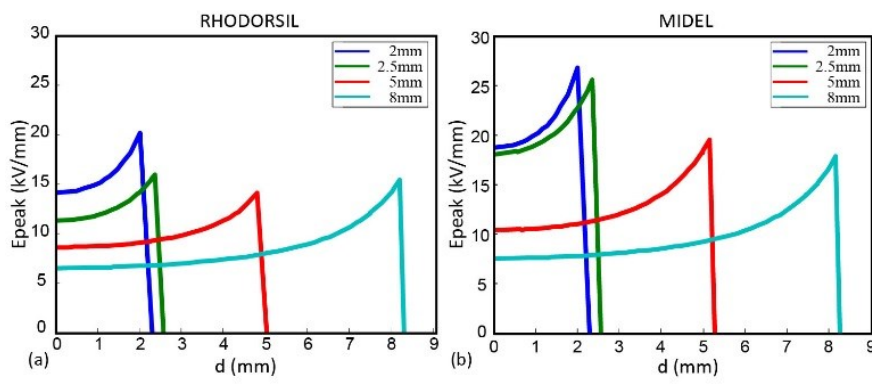

Figure 5. Field path with the most critical electrical field for different distances between the two tubes and the grounded plate for a) MIDEL $7131 \mathrm{~b}$ ) for RHODORSIL 604 V 50.

Table 3. Result field shape ring geometry setup.

\begin{tabular}{|c|c|c|c|c|c|}
\hline Type of oil & $\begin{array}{c}\text { Distance } \\
\boldsymbol{d} \text { [mm] }\end{array}$ & $\begin{array}{c}\text { Mean } \\
\text { breakdown } \\
\text { voltage } \mathbf{V}_{\mathbf{b r}} \\
{[\mathbf{k V}]}\end{array}$ & $\begin{array}{c}\text { Standard } \\
\text { deviation } \\
{[\mathbf{k V}]}\end{array}$ & $\begin{array}{c}\text { Peak } \\
\mathbf{E a v}= \\
\mathbf{V}_{\mathbf{b r}} / \mathbf{d} \\
{[\mathbf{k V} / \mathbf{m m}]}\end{array}$ & $\begin{array}{c}\text { breakdown } \\
\text { field } \\
\text { simulated } \\
{[\mathbf{k V} / \mathbf{m m}]}\end{array}$ \\
\hline & 2 & 31.44 & 3.77 & 15.72 & 20.15 \\
RHODORSIL & 2.5 & 32.85 & 3.24 & 13.14 & 16.00 \\
& 5 & 50.44 & 3.59 & 10.09 & 15.58 \\
& 8 & 67.16 & 2.33 & 8.40 & 15.43 \\
\hline MIDEL & 2 & 41.77 & 1.14 & 20.88 & 26.80 \\
& 2.5 & 52.49 & 2.8 & 21.00 & 25.56 \\
& 5 & 64.47 & 7.97 & 12.89 & 19.92 \\
& 8 & 79.275 & 8.00 & 9.91 & 17.9 \\
\hline
\end{tabular}

\section{TEST OF AN INSULATION SYSTEM COMBINING SEVERAL INSULATION MATERIALS}

\subsection{TESTED ASSEMBLY DESCRIPTION}

When combining different insulation material with known electrical characteristics, it becomes difficult to clearly identify the weak point of the insulation system. For this purpose a prototype assembly combining the solid, liquid and wire insulation has been built for destructive tests purposes. The assembly is composed of a wire in contact with a solid insulation plate of $1 \mathrm{~mm}$ thickness separated from a grounded plate by a layer of $2 \mathrm{~mm}$ of oil. The assembly is depicted in Figure 6.

In order to investigate the effect of pulse length on the breakdown voltage, a double exponential with a front time of $1 \mu \mathrm{s}$ and a time to half-value of $900 \mu \mathrm{s}$ is used. The voltage is recorded on an oscilloscope to measure the time before breakdown.

\subsection{RESULTS}

The results of the breakdown voltage for the different configurations of the assembly are summarized in Table 4. The time to breakdown from the beginning of the pulse is generally included between $10 \mu \mathrm{s}$ and $60 \mu \mathrm{s}$.

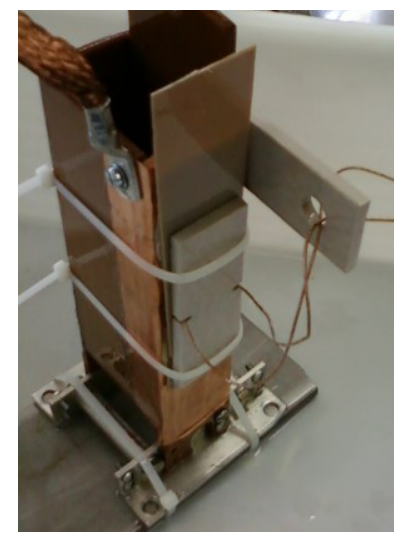

Figure 6. Assembly used for the destructive tests on the insulation assembly.

Table 4. Breakdown voltages for different configurations of the assembly.

\begin{tabular}{|c|c|c|c|c|}
\hline Oil & Support & Wire & $\begin{array}{c}\text { Breakdown } \\
\text { voltage } \\
{[\mathrm{kV}]}\end{array}$ & $\begin{array}{c}\text { Std. } \\
\text { deviation } \\
{[\mathrm{kV}]}\end{array}$ \\
\hline \multirow{4}{*}{ Used MIDEL } & \multirow{3}{*}{ PEEK } & Enameled & 71.3 & 7.4 \\
\hline & & One layer mica & 80.0 & 1.6 \\
\hline & & Two layers mica & 79.0 & 12.6 \\
\hline & G11 & One layer mica & 74.0 & 2.8 \\
\hline \multirow{2}{*}{ New MIDEL } & PEEK & \multirow{2}{*}{ One layer mica } & 91.8 & 15.7 \\
\hline & G11 & & 95.0 & 0 \\
\hline \multirow{2}{*}{$\begin{array}{c}\text { Used } \\
\text { RHODORSIL }\end{array}$} & PEEK & \multirow{2}{*}{ One layer mica } & 67.8 & 4.3 \\
\hline & G11 & & 71.9 & 8.2 \\
\hline
\end{tabular}

\subsection{RESULTS ANALYSIS}

The speed of streamer in oil for low breakdown voltages is in the order of $1 \mathrm{~km} \mathrm{~s}^{-1}$ [2]. The time from the beginning of the pulse to the breakdown is compatible with the time that the streamer takes to propagate into the $2 \mathrm{~mm}$ of oil gap. Once the streamer has propagated through the oil, the electrical field in the support is high enough to cause the breakdown of the support insulator.

The type and quality of oil is the main factor determining the breakdown voltage. For RHODORSIL oil the breakdown voltage is the lowest, between 67.8 and $71.9 \mathrm{kV}$, for used MIDEL between 71.3 and $80 \mathrm{kV}$ and the highest breakdown voltage is held from for new MIDEL oil, between 91.8 and 95 $\mathrm{kV}$. The electrical field at breakdown voltage in the assembly with a PEEK support, one layer mica insulation wire and used MIDEL oil is simulated with finite element methods (Figure 7). The electrical field inside the support is lower than the field 
achieved during the test of solid material. The field in the oil between the grounded plate and the support is equal to the breakdown field measured for the oil. It confirms that the streamer initiate and propagate first in the oil.

The influence of one particular component of the insulation can be assessed by exchanging it for a component of another type without replacing the other materials.

The three first tests with used MIDEL oil and PEEK support can be used to examine the influence of the type of wire insulation. The results are similar to the test of the wires only. The breakdown voltage increases by roughly $10 \%$ between enameled and mica insulated wire and there is no significant difference between wires with one or two layers of mica.

The measurement incertitude is too high compared to the influence of the support. The streamer starts in the oil, the only impact of the support is its permittivity which modifies the electric field distribution between oil and the solid support.

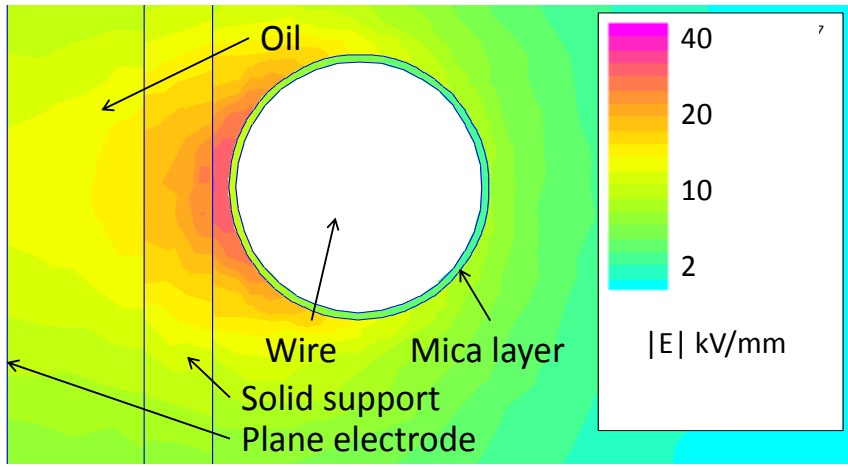

Figure 7. Simulation showing the electrical field on a section of the assembly.

\section{EFFECTS OF SAFETY FACTORS ON TRANSFORMER PERFORMANCES}

Once the breakdown field has been determined, a safety factor is considered to ensure that no breakdown will occur. The determination of this factor is based on experience and empirical rules. An environment used for the optimal design of pulse transformer described in [3] is used to perform a sensitivity analysis of the performances versus the insulation safety factor selected for a high voltage pulse transformer.

The considered pulse transformer must produce $29 \mathrm{MW}$ pulses of $140 \mu \mathrm{s}$ length at $180 \mathrm{kV}$ secondary, $15 \mathrm{kV}$ primary. The voltage is considered as stabilized when the voltage at secondary remains within $\pm 0.45 \backslash \%$ of the nominal voltage. The time between the beginning of the pulse and stabilization must be lower than $8 \mu \mathrm{s}$ and the maximum allowed secondary voltage overshoot is $1 \%$.

The pulse transformer that has the smallest volume is found by an optimization procedure.

The safety factor is defined as the ratio between the breakdown field in the oil $\mathrm{E}_{\text {breakdown }}$ and the maximum electrical field in the oil insulation $\mathrm{E}_{\max }$ considered in the design phases.

$$
\text { safety factor }=\frac{E_{\text {breakown }}}{E_{\max }}
$$

The safety factor in the solid material is higher than the safety factor in oil (higher breakdown consequences).

The safety factor forces the insulation thickness. The other dimensions of the transformer will be changed in order to meet the specifications. The relative volume is expressed in percentage of the volume of a transformer with a safety factor of 1 .

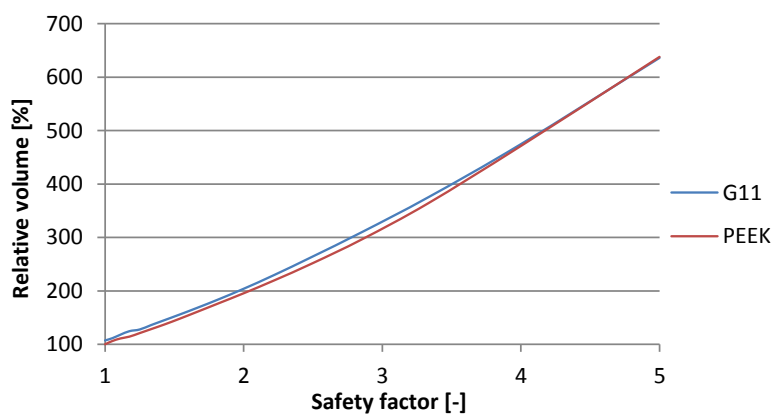

Figure 8. Influence of the insulation safety factor on the overall transformer volume.

Figure 8 shows the relation between the safety factor and the volume of the pulse transformer. The support material does not influence significantly the size. For low safety factor the relation is approximately proportional. For safety factor above 3 , the volume of the transformer increase more rapidly.

\section{CONCLUSION}

Combining experimental breakdown tests and Finite element Analyses of the same set-up, allows to easily determining the actual electrical field distribution inside the insulation material under evaluation. As soon as the electrical field distribution becomes inhomogeneous because of a complex geometry, and when an insulation system is composed of different materials, numerical field's simulations are necessary to identify the weak point in the insulation system/assembly. Alternatively, insulation materials datasheets can be directly used for FEA. In the specific case of $\mathrm{HV}$ pulse transformers the weakest point where a breakdown phenomenon starts is in the oil. The selected insulation safety factor greatly influences the pulse transformer optimization in terms of volume (and cost).

\section{ACKNOWLEDGMENT}

This work is supported by CERN, Switzerland where the high voltage tests have been realized.

\section{REFERENCES}

[1] H. Murase, S. Okabe, T. Kumai, H. Takakura, M. Takahashi and H. Okubo, "Systematization of insulation design technology for various electric power apparatus," Dielectrics and Electrical Insulation, IEEE Transactions on, vol.13, no.2, pp.400,407, April 2006

[2] R.E. HEBNER, "Measurement of electrical breakdown in liquids", liquids", in The liquid state and Its Electrical Properties, 1987, p. 519537, Plenum Press, New York and London.

[3] S. Candolfi, P. Viarouge, D. Aguglia and J. Cros, "Finite element based optimal design approach for high voltage pulse transformers", Pulsed Power Conference (PPC), San Francisco 2013, pp.1-6.

[4] S. Blume, and J. Biela, Optimal Transformer Design for Ultraprecise Solid State Modulators, IEEE Transactions on Plasma Science, Oct. 2013, pp. 2691-2700 